\title{
"Paciente-problema": imaginário coletivo de enfermeiros acerca do usuário com diagnóstico de esquizofrenia
}

\author{
I ${ }^{1}$ Débora Cristina Joaquina Rosa, ${ }^{2}$ Daiane Marcia de Lima, ${ }^{3}$ Lilian Miranda, \\ ${ }^{4}$ Rodrigo Sanches Peres I
}

Resumo: O estudo teve por objetivo compreender crenças e emoçóes acerca do usuário com diagnóstico de esquizofrenia vigentes no imaginário coletivo de enfermeiros inseridos na Atenção Primária à Saúde. Trata-se de estudo de abordagem qualitativa pautado pelo método investigativo psicanalítico. Os participantes foram 15 enfermeiros que atuavam no referido nível de atenção em saúde de uma cidade de médio porte. A coleta de dados foi realizada com o emprego do Procedimento de Desenho-Estória com Tema (PDE-T) e a análise de dados buscou captar campos de sentido mediante a execução dos movimentos técnicos preconizados para a operacionalização do método investigativo psicanalítico. Verificou-se que, de modo náo-consciente, o usuário com diagnóstico de esquizofrenia é representado negativamente no imaginário coletivo dos participantes, pois é visto como alguém inconveniente, que cria alvoroço e desperta medo, sobretudo devido à sua "agitação" supostamente típica. Assim, deparar-se com tal usuário corresponde, para os participantes, a uma situação a ser "resolvida" com rapidez. Este estudo, portanto, demarca dificuldades no tocante à atenção em saúde mental oferecida ao usuário com diagnóstico de esquizofrenia, as quais estão relacionadas a elementos não-conscientes da subjetividade grupal que, ao mesmo tempo, possuem caráter social e individual.

> Palavras-chave: imaginário coletivo; enfermagem; saúde mental; atenção primária à saúde; esquizofrenia.

\author{
1 Programa de Pós-Graduação em \\ Psicologia, Universidade Federal \\ de Uberlândia. Uberlândia-MG, \\ Brasil (deborarosa.psicologia@ \\ gmail.com). \\ ORCID: 0000-0003-1468-2471 \\ ${ }^{2}$ Programa de Pós-Graduação em \\ Psicologia, Universidade Federal de \\ Uberlândia. Uberlândia-MG, Brasil \\ (daianemarcia@yahoo.com.br). \\ ORCID: 0000-0002-6613-3282 \\ ${ }^{3}$ Escola Nacional de Saúde Pública \\ Sergio Arouca, Fundação Oswaldo \\ Cruz. Rio de Janeiro-RJ, Brasil \\ (lilian.miranda@ensp.fiocruz.br). \\ ORCID: 0000-0002-8238-8111 \\ ${ }^{4}$ Programa de Pós-Graduação em \\ Psicologia, Universidade Federal de \\ Uberlândia. Uberlândia-MG, Brasil \\ (rodrigosanchesperes@ufu.br). \\ ORCID: 0000-0002-2957-7554
}

Recebido em: 05/08/2020 Aprovado em: 07/12/2020 Revisado em: 20/01/2021 


\section{Introdução}

A assistência a pessoas em sofrimento psicossocial é uma das incumbências dos serviços públicos de saúde, quer sejam especializados em saúde mental ou não, como os Centros de Atenção Psicossocial (CAPSs) e as Unidades Básicas de Saúde (UBSs), respectivamente. Tal modalidade de sofrimento pode se apresentar sob formas e intensidades muito variadas, a depender de múltiplos fatores, como a constituição psíquica do sujeito, sua inserção familiar, social, histórica e cultural e suas condiçôes socioeconômicas, por exemplo. Um dos diagnósticos associados ao sofrimento psicossocial considerados mais graves é a esquizofrenia, descrita como um transtorno mental que acarreta importantes prejuízos ao funcionamento global, pois se caracteriza pela ocorrência de alucinaçôes, delírios, discurso incoerente, comportamento desorganizado, embotamento afetivo, retraimento social e autocuidado comprometido, sintomas que devem estar presentes na maior parte do tempo por no mínimo um mês para a confirmação do caso, mas podem se perpetuar indefinidamente (OMS, 1993).

No que se refere à estruturação da atenção psicossocial, Amarante e Nunes (2018) destacam que a Reforma Psiquiátrica Brasileira (RPB) se afigura como um processo social abrangente, cujos objetivos centrais - ainda não efetivados por completo - são a construção de um novo lugar social para os portadores de transtornos mentais e a transformação das práticas institucionalizantes às quais os mesmos, em sua maioria, eram submetidos sob a égide do modelo hospitalocêntrico, hegemônico no país até o início dos anos 2000. Desse modo, a operacionalização da RPB, desde a perspectiva técnico-assistencial, depende da organização de uma rede constituída por variados pontos de atenção, atualmente denominada Rede de Atenção Psicossocial - RAPS (BRASIL, 2011). Cumpre assinalar que serviços públicos de saúde relativos à Atenção Primária em Saúde (APS) - como as UBSs - também devem integrar tal rede, para que esta possa oferecer um cuidado territorial compatível com a globalidade das demandas dos usuários e valorizá-los como cidadãos (CAMPOS; BEZERRA; JORGE, 2020; TANAKA; RIBEIRO, 2009).

Ainda que reconhecido como essencial por profissionais de saúde e pesquisadores, o cuidado em saúde mental no âmbito da APS enfrenta uma série de desafios, dentre os quais sentimentos de medo e incompetência reportados por muitos daqueles que estabelecem contato direto com usuários tradicionalmente 
designados como "loucos" e fragilidades no que tange à formação e à capacitação profissional (FERNANDES; MATSUKURA; LOURENÇO, 2018; JUCÁ; NUNES; BARRETO, 2009). Nessa conjuntura, em contraste com os princípios da RPB, observa-se certa propensão à oferta de respostas medicalizadoras, pautadas em atividades assistenciais que desconsideram o contexto social e os vínculos das pessoas em sofrimento psicossocial, gerando o enquadramento arbitrário dos comportamentos das mesmas em categorias nosológicas (GAMA; ONOCKOCAMPOS; FERRER, 2014; TESSER; POLI NETO; CAMPOS, 2010).

Sabe-se que, ao enfermeiro que atua na APS, compete planejar, gerenciar, coordenar, executar e avaliar açōes de saúde, inclusive de saúde mental (AMARANTE et al., 2011; MATUMOTO et al., 2011). Porém, a literatura científica revela que, no Brasil, o potencial inerente a tal profissional de saúde muitas vezes não chega a ser efetivado junto a pessoas em sofrimento psicossocial no referido nível de atenção em saúde (MARTINS et al., 2018, LIMA; GARCIA; TOLEDO, 2013, CASTRO; FUREGATO, 2008, GIACON; GALERA, 2006, OLIVEIRA; ATAÍDE; SILVA, 2004). É possível propor que a situação em questão, ao menos em parte, está associada ao fato de que o trabalho dos profissionais de saúde como um todo comumente é atravessado por determinantes não-conscientes, enraizados no ambiente humano habitado pelos mesmos, como revela o estudo empreendido por Simóes (2012) visando, neste grupo social, à exploração psicanalítica do imaginário coletivo acerca do "paciente psiquiátrico".

O conceito de imaginário coletivo, à luz da Psicanálise, diz respeito ao complexo ideo-afetivo constituído, essencialmente, por crenças e emoçóes que se sobressaem como o cerne da subjetividade grupal e, assim, modelam de modo náo-consciente a generalidade das manifestaçôes de determinado conjunto de pessoas em relação a um público ou a um fenômeno em específico (MANNA; LEITE; AIELLOVAISBERG, 2018; GRANATO; TACHIBANA; AIELLO-VAISBERG, 2011; AIELLO-VAISBERG; AMBROSIO, 2006). Tal complexo, portanto, equivale ao substrato lógico-emocional das produçóes humanas, imaginativas ou concretas, conforme originalmente propôs Aiello-Vaisberg (1999). Cumpre assinalar que, como apontam Rosa et al. (2019), diversas pesquisas realizadas a partir dos anos 2000 produziram um corpo de conhecimentos em função do qual é possível afirmar que o conceito de imaginário coletivo constitui importante acréscimo brasileiro ao vocabulário psicanalítico contemporâneo. 
Por essa razão, Rosa et al. (2019) defendem que novas pesquisas desenvolvidas em torno do conceito psicanalítico de imaginário coletivo podem levar à emergência de insights valiosos quanto a uma ampla gama de temáticas psicossociais acerca das quais ainda não há um entendimento mais aprofundado. Partindo de tal princípio, o presente estudo teve por objetivo compreender crenças e emoçóes acerca do usuário com diagnóstico de esquizofrenia vigentes no imaginário coletivo de enfermeiros inseridos na APS. Ressalte-se que o estudo se afigura como um recorte de uma pesquisa mais ampla, a qual distinguiu-se de outras consagradas a assuntos afins - como aquelas assinadas por Martins et al. (2018), Lima, Garcia e Toledo (2013) e Castro e Furegato (2008) - pela especificidade de seu foco, definido pela preocupação com a demarcação de bases ideo-afetivas não-conscientes da atenção em saúde ofertada pelos referidos profissionais de saúde ao público em questáo.

\section{Método}

Trata-se de estudo de abordagem qualitativa pautado pelo método investigativo psicanalítico, o qual, conforme Herrmann (2017), visa à ampliaçáo do leque de possibilidades de compreensão acerca da psique, tanto individual quanto social. Logo, o método investigativo psicanalítico - pormenorizado em termos de seus movimentos técnicos no segmento do texto relativo à análise de dados - não está restrito a dispositivos clínicos, inclusive porque, segundo o referido autor, antecede os sistemas teóricos psicanalíticos e as modalidades terapêuticas deles derivados, na medida em que proporciona acesso aos elementos que lhes conferem sustentação. Por essa razão, o método investigativo psicanalítico se presta à exploração de temáticas psicossociais que, a partir de uma leitura mais superficial, poderiam parecer externas ao universo psicanalítico. E diversas pesquisas sobre o imaginário coletivo confirmam tal fato (MANNA; LEITE; AIELLO-VAISBERG, 2018; GRANATO, TACHIBANA; AIELLO-VAISBERG, 2011; PONTES et al., 2010; AIELLO-VAISBERG; AMBROSIO, 2006).

Outrossim, Herrmann (2017) argumenta que as pesquisas pautadas pelo método investigativo psicanalítico propóem trazer à tona as regras não-conscientes que estruturam emaranhados de ideias e afetos, bem como qualifica a interpretação como uma ferramenta imprescindível diante desse desafio. Em suas palavras, a propósito, a Psicanálise foi definida como a "ciência artística da interpretação" (p. 141). Tendo 
em vista o que precede, depreende-se que a prática da interpretação psicanalítica admite apenas uma sistematização parcial, pois não consiste na explicação de determinada produção humana amparada no emprego canônico de teorias, mas, sim, na construção de novas formulaçôes sobre suas significações latentes por meio do exame de representaçôes figurativas. Não resta dúvidas sobre isso observando-se a démarche de Freud, tanto em seus casos clínicos quanto em suas obras sociológicas, como sublinha Enriquez (2005).

\section{Participantes}

Participaram do estudo 15 enfermeiros que atuavam em diversos serviços públicos de saúde relativos à APS em um dos distritos sanitários de uma cidade de médio porte de Minas Gerais, os quais foram recrutados em uma reuniáo de rotina, como será detalhado adiante. Apenas um deles era do sexo masculino, e todos possuíam no mínimo um ano de experiência profissional em tal nível de atenção à saúde.

Os participantes concordaram em contribuir voluntariamente com a pesquisa que originou este estudo, tendo, para tanto, assinado um Termo de Consentimento Livre e Esclarecido após a apresentação de informações sobre os cuidados éticos que seriam observados quanto à coleta de dados e à divulgação de resultados. A propósito, faz-se necessário mencionar que o estudo foi submetido (CAAE 80465717.6.0000.5152) e aprovado por um comitê de ética em pesquisa de uma universidade pública (Parecer 2.496.299, de 15 de fevereiro de 2018).

\section{Instrumento}

Assim como nas pesquisas sobre o imaginário coletivo em sua acepção psicanalítica assinadas por Manna, Leite e Aiello-Vaisberg (2018), Pontes et al. (2010) e Russo, Couto e Aiello-Vaisberg (2009), dentre outras, a coleta de dados, neste estudo, foi realizada mediante o emprego do Procedimento de Desenho-Estória com Tema (PDE-T), instrumento cuja finalidade precípua é favorecer a expressão emocional em um contexto relacional (AIELLO-VAISBERG; AMBRÓSIO, 2013).

Trata-se de uma estratégia de investigação dialógica criada por Aiello-Vaisberg (1999) com base na perspectiva epistemológica intersubjetiva estabelecida pela Psicanálise, especialmente em suas vertentes contemporâneas, a qual se opõe ao viés positivista e presume que conhecimentos científicos válidos não derivam apenas do exame de fenômenos mensuráveis de forma objetiva (TACHIBANA, 2011). Faz- 
se necessário esclarecer que o PDE-T pode ser utilizado tanto individual quanto coletivamente, sendo que a tarefa proposta aos participantes da pesquisa é a produção de um desenho sobre o assunto definido pelo pesquisador e, a seguir, a elaboração de uma estória a respeito do desenho e a criação de um título para a mesma.

\section{Coleta de dados}

A coleta de dados foi conduzida junto a enfermeiros que atuavam na APS de um distrito sanitário ao qual as pesquisadoras possuíam acesso. Nesse sentido, os participantes constituíram uma amostra intencional. Após as devidas autorizaçôes institucionais, a pesquisa que originou este estudo foi divulgada - em termos de seus objetivos, procedimentos e cuidados éticos - junto à população-alvo durante uma reunião de rotina. Contudo, levando em conta que as características do espaço físico em que ocorria tal reuniáo dificultavam a interação verbal e o contato visual entre os enfermeiros que se dispuseram a participar, os mesmos foram orientados pelas duas pesquisadoras responsáveis pela coleta de dados a realizarem a tarefa proposta de maneira individual e concomitante, a exemplo do que ocorreu nas pesquisas de Pontes et al. (2010) e Russo, Couto e Aiello-Vaisberg (2009).

Empregando o PDE-T como instrumento, as pesquisadoras solicitaram que os participantes - sem consultarem uns aos outros - desenhassem um usuário com diagnóstico de esquizofrenia em atendimento por um enfermeiro na APS, redigissem uma estória sobre o desenho, dando-lhe um título, bem como informassem, por escrito, sexo, idade e tempo de experiência como enfermeiro. Ressalte-se que as pesquisadoras não estabeleceram limite de tempo para a conclusão da tarefa. Ademais, deve-se salientar que, no segmento do texto relativo aos resultados, serão veiculadas informaçóes complementares acerca da coleta de dados, especialmente no que diz respeito ao processo de entrada no cenário de pesquisa, na medida em que tais informaçóes tratam de acontecimentos que, em última instância, se afiguram como achados.

\section{Análise de dados}

$\mathrm{Na}$ esteira de pesquisas prévias sobre o imaginário coletivo em sua acepção psicanalítica (MANNA; LEITE; AIELLO-VAISBERG, 2018; GRANATO; TACHIBANA; AIELLO-VAISBERG, 2011; BARCELOS; TACHIBANA; AIELLO-VAISBERG, 2010), os dados coletados foram analisados buscando- 
se captar campos de sentido. Neste estudo, foram visados os campos de sentido que sustentam o imaginário coletivo dos participantes a propósito do usuário com diagnóstico de esquizofrenia. Vale destacar que os campos de sentido são formados por conteúdos - primariamente intraindividuais, mas também intersubjetivos definidores de posicionamentos de determinado grupo social quanto a um certo fenômeno (AIELLO-VAISBERG; AMBROSIO, 2013). Para viabilizar a captação dos campos de sentido, recorreu-se aos movimentos técnicos recomendados por Herrmann (2001) para a operacionalização da prática da interpretação psicanalítica e, por extensão, do método investigativo psicanalítico.

Tais movimentos técnicos se encontram entrelaçados e consistem, basicamente, em realizar sucessivas leituras não-seletivas do corpus de análise - composto pelo material empírico como um todo - de modo a explorar a pluralidade de significaçóes possíveis para além daquelas manifestas mais diretamente e, então, em construir uma via de compreensão sobre as mesmas, com foco nas regras não-conscientes que podem tê-las estruturado (HERRMANN, 2001). Ao longo de uma série de reunióes, duas das pesquisadoras, priorizando uma atitude de disponibilidade receptiva, examinaram o corpus de análise em consonância com as referidas recomendações, sendo que, posteriormente, as formulaçóes produzidas à custa de tal expediente foram discutidas e validadas durante uma reuniáo do respectivo grupo de pesquisa, acompanhando uma estratégia recorrentemente utilizada em pesquisas sobre o imaginário coletivo em sua acepção psicanalítica.

Como mencionado, a prática da interpretação psicanalítica admite apenas uma sistematização parcial. Não obstante, a partir da discriminação dos movimentos técnicos que colocam em ação o método investigativo psicanalítico, esclarece-se que, neste estudo, a análise de dados pode ser subdividida, para fins didáticos, em duas etapas básicas. $\mathrm{O}$ trabalho desenvolvido pelas pesquisadoras na primeira etapa, ou seja, durante a realização de sucessivas leituras não-seletivas do corpus de análise, remete à atenção flutuante adotada pelos psicanalistas em modalidades terapêuticas para, conforme Laplanche e Pontalis (2000), se eximirem de prejulgamentos e não imputarem importância particular a conteúdos selecionados a priori dentre aqueles apresentados por seus pacientes.

Já na segunda etapa, cujo objetivo foi fazer emergir do corpus de análise significaçóes latentes, as pesquisadoras lançaram mão de uma atitude de receptividade ativa. Dessa forma, detiveram-se nas principais linhas de força identificadas nos 
campos de sentido delineados na primeira etapa para, então, estabelecer com maior precisão seus contornos. Assim, a segunda etapa pode ser qualificada como um processo de depuração. Em síntese, portanto, é possível afirmar que foram utilizadas consecutivamente na análise de dados do presente estudo as duas palavras de ordem preconizadas por Herrmann (2001) para a construção de conhecimentos psicanalíticos: "deixar que surja" e "tomar em consideração".

\section{Resultados}

Julgou-se pertinente iniciar este segmento do texto com informaçóes complementares sobre o processo de entrada no cenário de pesquisa, a fim de abordar acontecimentos que podem ser enquadrados como achados. Ademais, a veiculação de informaçóes sobre tal tópico em particular tem sido cada vez mais valorizada como indicador de transparência em pesquisas qualitativas (CLARK, 2003). Assim, cabe esclarecer que a coleta de dados fora acordada previamente com o articulador do distrito sanitário que, reconhecendo a relevância e a viabilidade da pesquisa da qual deriva este estudo, comprometeu-se a reservar um período de uma hora, durante uma das reunióes realizadas periodicamente com os enfermeiros, para a coleta de dados.

Contudo, devido a mudanças de cargo, um novo profissional assumiu a função de articulador e, após três semanas de tentativas de contato, o mesmo confirmou que a coleta de dados poderia ser realizada na data anteriormente definida, porém anunciou que não seria mais possível dispor de uma hora para tanto. E não apresentou uma alternativa clara a esse respeito. De qualquer forma, duas pesquisadoras compareceram à reunião e lá souberam que os enfermeiros presentes não haviam sido informados - pelo antigo articulador e tampouco pelo novo - sobre a realização da pesquisa, ao contrário do que fora combinado. Além disso, as pesquisadoras foram notificadas de que deveriam apresentar a pesquisa e realizar a coleta de dados durante o intervalo da reunião, sem duração especificada. E assim foi feito, tendo sido registradas apenas seis recusas.

Cumpre assinalar que foi observado que os participantes ficaram agitados com a tarefa proposta pelas pesquisadoras. A maioria, inclusive, começou a desenhar tão logo recebeu a folha de papel, utilizando canetas de que já dispunham, ao invés dos lápis que seriam distribuídos após a apresentação das instruções iniciais. Para além 
da natureza propriamente dita da tarefa, parece razoável cogitar que a "pressa" dos participantes, ao menos em parte, também está relacionada ao processo de entrada no cenário de pesquisa, que foi um tanto atribulado, conforme exposto. Há, ainda, que se levar em conta que os participantes podem ter se sentido pressionados pelo tempo, embora não tenha sido especificada pelo articulador - quer seja aos próprios participantes ou às pesquisadoras - qual seria a duração do intervalo da reunião.

Faz-se necessário sublinhar ainda que, quando da entrega das folhas de papel, alguns participantes fizeram comentários sobre a situação a ser contemplada no desenho. Um deles afirmou: "Não sei o que fazer. Chama o bombeiro". Outro comentou: "Chama o psicólogo". Após tal comentário, um terceiro participante, em tom jocoso, disse o seguinte, dirigindo-se às pesquisadoras: "Esse desenho tinha que ser feito por vocês, que são psicólogas. Essa é a área de vocês”. É relevante apontar também que alguns participantes afirmaram que não sabiam desenhar. Mas todos aqueles que haviam se disposto inicialmente finalizaram a tarefa após serem informados que poderiam desenhar como quisessem e que não havia expectativa de que os desenhos expressassem habilidades artísticas. O tempo empregado pela maioria dos participantes para a conclusão da tarefa propriamente dita - ou seja, sem considerar a apresentação das instruçóes - foi de aproximadamente 10 minutos, mas um participante consumiu apenas dois minutos e outro, vinte minutos.

Posto isso, será apresentado e discutido a seguir o campo de sentido que responde ao objetivo do estudo de modo mais direto, o qual foi denominado "O pacienteproblema”. Este campo de sentido foi organizado ao redor de crenças e emoçôes predominantemente negativas por meio das quais o usuário com diagnóstico de esquizofrenia parece ser representado no imaginário coletivo dos participantes. A qualidade desta representação seria determinada, em especial, pelo fato de tal usuário ser visto como alguém inconveniente, que cria alvoroço, sobretudo devido à sua "agitação" supostamente típica, característica citada em um excerto da estória do participante 1: "Paciente chega na UBSF agitada, referindo que queria morrer [...]".

$\mathrm{O}$ excerto inicial da estória do participante 8 igualmente alude à característica em questão: "Paciente [...] agitado, falando alto, reclamando da demora. Conversa com a recepcionista exigindo ser atendido de imediato". Por outro lado, um excerto da estória do participante 9 sugere que o rótulo de "paciente-problema" se aplicaria ao usuário com diagnóstico de esquizofrenia também porque, nos participantes, a 
possibilidade humana de perda da razão nele personalizada justificaria o despertar de um grande temor: "[...] As administrativo [sic] já sai apavorada [quando um usuário com diagnóstico de esquizofrenia chega ao serviço de saúde] e chama a enfermeira”.

Esse temor explicaria por que deparar-se com um usuário com diagnóstico de esquizofrenia corresponde, para os participantes, a uma situação a ser "resolvida" com rapidez, o que, no desenho elaborado pelo participante 5 (figura 1), por exemplo, foi feito por um enfermeiro à custa da administração de um psicofármaco por meio de uma injeção, expediente este que, notoriamente, proporciona uma ação mais rápida do princípio ativo. É interessante destacar ainda que, à direita do desenho, vê-se o que seria uma atividade grupal acompanhando a situação relatada na estória. Mas o participante não esclareceu qual seria a relação existente entre a aplicação da injeção e a atividade grupal. Seria a primeira uma espécie de preparação para a segunda? Ou simplesmente um recurso voltado à contenção de um sintoma que desperta nos profissionais de saúde o sentimento de urgência? Arriscar uma resposta definitiva seria precipitado.

\section{Figura 1. Desenho elaborado pelo participante 5}

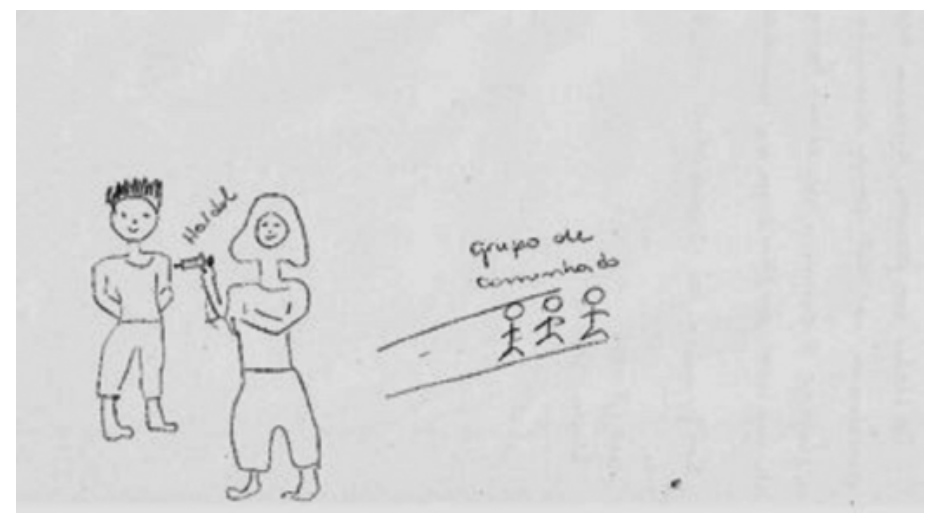

Os achados do presente estudo ainda subsidiam a associação entre o "tormento" supostamente vivenciado pelo usuário com diagnóstico de esquizofrenia e as alteraçóes do juízo de realidade que constituem o quadro clínico deste transtorno mental, como se vê no desenho elaborado pelo participante 2 (figura 2). Ocorre que o personagem retratado nesta produção gráfica parece experimentar alucinaçóes - 
auditivas e olfativas, especificamente - e delírios, o que amedronta os profissionais de saúde, como se vê no seguinte excerto da respectiva estória: “[...] É preciso preparo profissional para esse acolhimento, que na maioria das vezes gera medo frente à uma crise aguda”. Já o excerto inicial da estória do participante 9, em certo aspecto, remete a outro sintoma da esquizofrenia: "Paciente chega desconfiado na unidade [...]". Isso porque a "desconfiança" mencionada poderia ser compreendida, em termos técnicos, como persecutoriedade.

\section{Figura 2. Desenho elaborado pelo participante 2}

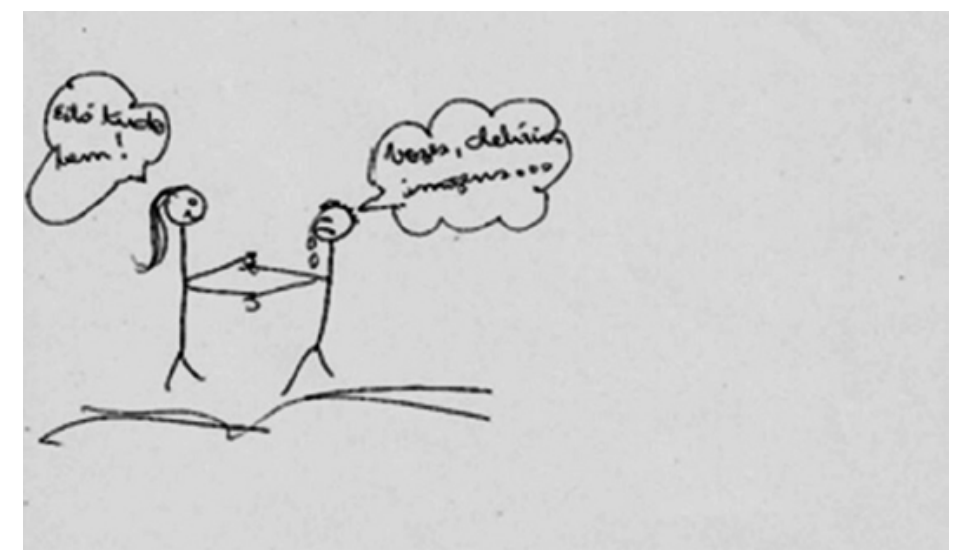

Deve-se acrescentar que, na estória do participante 1, medo é o sentimento experimentado pelo próprio usuário com diagnóstico de esquizofrenia, o que justificaria sua "agitação". No desenho deste participante (figura 3), o medo é associado à sintomatologia do transtorno mental, pois há uma representação pictórica de um "homem de preto" e de um "cachorro preto" que estariam tentando matar o personagem. E é interessante sublinhar que ambos foram posicionados em um baláo pontilhado, recurso tradicionalmente utilizado em histórias em quadrinhos para expressar a imaginação. Ademais, em um excerto da estória do participante 12 igualmente se nota o estabelecimento de uma causalidade entre o medo e a agitação - neste caso, simbolizada pelo pranto - do usuário com diagnóstico de esquizofrenia: "Paciente chega unidade aos prantos dizendo que precisa muito passar pelo psiquiatra, está com medo e está muito mal”. 
Figura 3. Desenho elaborado pelo participante 1

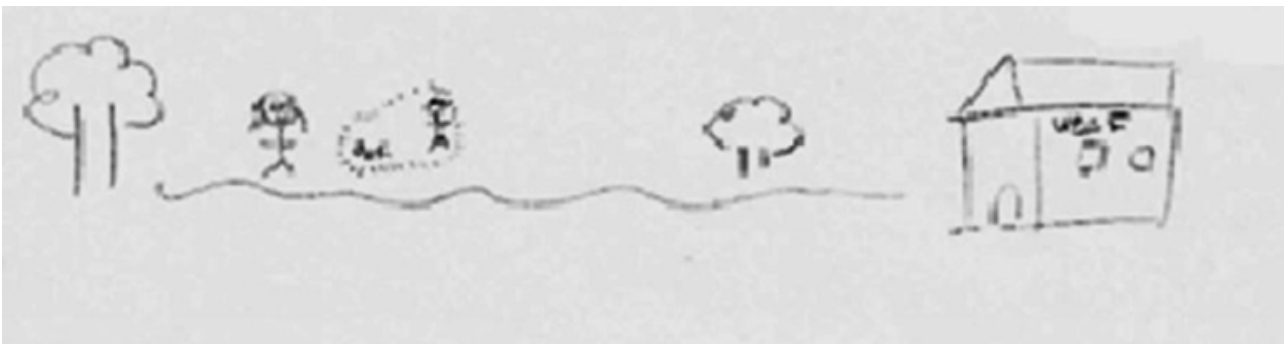

Outro aspecto que chama a atenção é o fato de que as produçóes gráficas e verbais da maioria dos participantes do estudo contemplam apenas a fase ativa da esquizofrenia, o que parece decisivo para a emergência do rótulo de "pacienteproblema”. Inclusive, justamente por se encontrarem em tal fase, em certos casos os usuários retratados são conduzidos ao serviço de saúde por familiares. E, a partir do que se pode depreender das estórias, a rigor competiria a esses usuários apenas seguir passivamente as recomendaçôes dos profissionais de saúde. $O$ seguinte excerto da estória do participante 4 pode ser considerado emblemático quanto a isso: "Paciente comparece a unidade de saúde, com diagnóstico de esquizofrenia, [...] é encaminhado para avaliação". O mesmo se aplica à sucinta produção verbal apresentada pelo participante 11, em que "encaminhar" também é o verbo principal: "Paciente em crise foi encaminhado para [nome de hospital] para atendimento". Já na estória elaborada pelo participante 7, fica claro o usuário não participa do processo de tomada de decisão sobre seu próprio futuro, conforme o excerto a seguir: "[...] após avaliação é feita uma abordagem multiprofissional com psicólogo e médico, que definirá o tratamento [...]".

\section{Discussão}

Como mencionado, verificou-se que o imaginário coletivo dos participantes sobre o usuário com diagnóstico de esquizofrenia é povoado por crenças e emoçóes predominantemente negativas. Em linhas gerais, Martins et al. (2018) obtiveram resultados semelhantes em outra pesquisa desenvolvida junto a enfermeiros que atuavam na APS, pois notaram que muitos deles definiam os rumos da assistência a ser ofertada ao público em questáo apoiando-se em informaçóes provenientes do senso comum, o que levaria à reproduçáo de preconceitos e estereótipos. Igualmente 
observou-se na referida pesquisa que o usuário com diagnóstico de esquizofrenia tendia a despertar medo e insegurança nos participantes, pois frequentemente era taxado como alguém que tumultua o serviço de saúde, podendo, inclusive, ser agressivo e violento.

Já Lima et al. (2013) investigaram os olhares assumidos por técnicos de enfermagem e enfermeiros frente ao usuário com diagnóstico de esquizofrenia. Como consequência, diferenciaram um olhar empírico e um olhar científico. O olhar empírico, constituído a partir da observação do cotidiano, fomentaria a atribuição ao usuário de características definidas de acordo com saberes populares. Contudo, se empregado de forma crítica e reflexiva, permitiria a valorização de certas facetas do processo saúde-doença que não são suficientemente compreendidas pela ciência. Já o olhar científico teria caráter claramente especializado, e suas principais implicaçôes seriam a subordinação da Enfermagem ao saber psiquiátrico e, no limite, a adoção de uma postura repressiva e vigilante. A existência de uma propensão a esse tipo de postura entre os participantes do estudo pode ser deduzida considerando que, conforme exposto, muitos deles aparentemente veem o usuário com diagnóstico de esquizofrenia como alguém que cria alvoroço.

Contudo, vigiar e reprimir são açóes incompatíveis com o papel que, segundo a revisão da literatura empreendida por Giacon e Galera (2006), competiria aos enfermeiros diante de um usuário com diagnóstico de esquizofrenia na perspectiva da reabilitação psicossocial, processo por meio do qual, sobretudo à custa da inserção comunitária, se deveria buscar a superaçáo do estigma associado ao transtorno mental. Para as autoras, aos enfermeiros caberia também contemplar diferentes aspectos biopsicossociais do processo saúde-doença-cuidado através da valorização do relacionamento interpessoal com o usuário e sua família, sendo que a realização de visitas domiciliares e de atividades assistenciais grupais nos serviços públicos de saúde foram apontadas como intervenções potencialmente proveitosas para tanto.

A exemplo de Lima et al. (2013), Simóes (2012) sublinha que a atenção em saúde mental é influenciada tanto por conhecimentos técnico-científicos quanto por valores socialmente compartilhados, oriundos de crenças e emoções que se fundem, configurando o imaginário coletivo. Ademais, a autora verificou que, no imaginário coletivo de um grupo de profissionais de saúde, foi recorrente a redução do "paciente psiquiátrico" à sua sintomatologia, o que pode fomentar uma atitude de "controle total" em relação ao mesmo. Em última instância, isso reforça que, 
como alertou Aiello-Vaisberg (1999), muitas vezes práticas excludentes decorrem de angústias vivenciadas por profissionais de saúde devido à qualificação inconsciente da "loucura" como uma condição assustadora e até mesmo contagiosa, o que, em certo aspecto, também foi observado nos participantes deste estudo.

Vale reforçar que o emprego de psicofármacos na assistência a pessoas em sofrimento psicossocial foi valorizado pelos participantes do estudo. Almeida (2010) reconhece a importância da terapêutica medicamentosa, sobretudo porque auxilia a controlar a agudização de alguns sintomas. Por outro lado, sublinha que o tratamento da esquizofrenia, na perspectiva da reabilitação psicossocial, não pode prescindir de um projeto terapêutico comprometido com um cuidado singularizado, apoiado na relação usuário-família-sociedade. Contudo, em um estudo teórico que soa bastante atual, apesar de ter sido publicado há mais de 15 anos, Oliveira e Alessi (2003) advertiram que muitos enfermeiros apresentam um discurso orientado para a desconstrução do saber psiquiátrico, mas, quando se deparam com demandas de saúde mental, limitam-se a empreender açóes que seguem o paradigma organicista - a exemplo daquelas retratadas em destaque no desenho do participante 5 - ou possuem um caráter burocrático-administrativo.

Como advertem Amarante e Nunes (2018), a RPB tem perseguido a construção de dispositivos clínicos, políticos, sociais e culturais em prol da superação da lógica asilar, produtora de segregação e isolamento. Porém, puderam ser identificados entre os participantes do presente estudo alguns resquícios daquilo que Simôes (2012) chamou de "antiga ordem", racionalidade em virtude da qual os profissionais de saúde assumem funções específicas, norteadas pela medicalização do sofrimento psicossocial. Como consequência, a internação psiquiátrica costuma ser considerada um recurso necessário para proteger aqueles que convivem com pacientes acometidos por transtornos mentais dos danos que estes seriam capazes de ocasionar. Um dos resquícios identificados foi, justamente, a preocupação com a rapidez dos atendimentos, já mencionada. Tal preocupação, a propósito, pode levar à subnotificação dos casos e ao estabelecimento de uma relação disciplinar autoritária com o público em questão (OLIVEIRA et al., 2004).

Quanto ao medo que o paciente com diagnóstico de esquizofrenia parece despertar nos participantes do estudo, é interessante mencionar que Castro e Furegato (2008) obtiveram achados congruentes em pesquisa que buscou identificar as atividades assistenciais desenvolvidas por um grupo de enfermeiros no cuidado ao usuário 
com diagnóstico de esquizofrenia. Os participantes da pesquisa reconheceram a complexidade inerente a tal trabalho, sobretudo devido a sintomas que consideram típicos, como heteroagressividade, delírios, alucinações e agitação psicomotora, os quais supostamente demandariam vigilância constante. Outros sintomas, porém, não foram mencionados, como a falta de interesse pelas pessoas e pelo meio. Para os autores, isso ocorreu porque esse segundo conjunto de sintomas não incomoda diretamente a equipe de saúde.

É oportuno recapitular que as produçôes gráficas e verbais dos participantes do estudo dizem respeito somente à fase ativa da esquizofrenia. Ocorre que, como observou Almeida (2010), tipicamente são reconhecidas três fases na evolução de tal transtorno mental. A fase prodômica é marcada por sintomas iniciais, mais leves e inespecíficos. Já a fase ativa engloba o chamado "surto psicótico", em que o usuário apresenta sintomas considerados mais graves, como delírios e alucinações. A fase latente, por fim, decorre do apaziguamento da crise. E, para os participantes, aparentemente a fase ativa da esquizofrenia conduz os profissionais de saúde ao exercício verticalizado do poder. Entretanto, Lima et al. (2013) defendem que enfermeiros podem e devem auxiliar usuários com diagnóstico de esquizofrenia a se reconhecerem como sujeitos reflexivos, responsáveis e capazes de retornar à vida social. Da mesma maneira, Araújo, Lemos e Carvalho (2007) salientam que, quando norteado pelo relacionamento terapêutico, o trabalho do enfermeiro junto a tal público tende a se revelar emancipatório e, como consequência, decisivo para seu processo de desinstitucionalização.

Para finalizar este segmento do texto, julgou-se pertinente - assumindo o risco de ultrapassar os limites do presente estudo - conjecturar de modo pontual sobre alguns fatores que, no nível macrossistêmico, possivelmente proporcionam um pano de fundo para a emergência e a persistência, no imaginário coletivo dos participantes, das crenças e emoçôes aqui mencionadas. Com base em entraves à RPB identificados previamente por uma série de autores, um desses fatores seguramente seria a formação dos profissionais de saúde como um todo no país, muitas vezes ainda pautada em concepçóes ultrapassadas sobre saúde mental, as quais tendem a simplificar artificialmente a complexidade das experiências humanas e, como consequência, contribuem para a perpetuação de práticas asilares (ONOCKO-CAMPOS, 2019; LEAL; SERPA JR., 2009). Outro fator seria a ausência de espaços de reflexão e educação permanente nos serviços públicos de saúde, sobretudo naqueles relativos à 
APS (GAMA; ONOCKO-CAMPOS; FERRER, 2014). Parece oportuno mencionar ainda a difusão insuficiente dos importantes resultados reportados por pesquisas nacionais que enfatizam o caráter singular e subjetivo dos processos de adoecimento e restabelecimento das pessoas em sofrimento psicossocial (SERPA JR. et al., 2017).

\section{Considerações finais}

Respondendo ao objetivo do presente estudo, o campo de sentido denominado " $\mathrm{O}$ paciente-problema” foi organizado em torno de crenças e emoções segundo as quais o usuário com diagnóstico de esquizofrenia, de modo preponderante, é representado negativamente no imaginário coletivo dos participantes. Constatou-se, em síntese, que o mesmo é visto pelos participantes como inconveniente, pois supostamente cria alvoroço nos serviços públicos de saúde relativos à APS ao despertar medo e desencadear situaçôes difíceis, que devem ser "resolvidas" rapidamente. E, além de dificultar a inclusão do usuário nas decisóes sobre seu próprio tratamento, a rapidez das açôes de saúde pode ser considerada potencialmente prejudicial porque tende a diminuir seu tempo de permanência em espaços que deveriam ser experimentados como acolhedores e promotores de convívio social.

Sendo assim, este estudo subsidia a demarcação de dificuldades no tocante à atenção em saúde mental oferecida ao usuário com diagnóstico de esquizofrenia, e avança em relação a pesquisas previamente desenvolvidas sobre a temática, devido à sua ênfase no imaginário coletivo em sua acepção psicanalítica. Afinal, esta ênfase lançou luz sobre elementos não-conscientes da subjetividade grupal que, ao mesmo tempo, possuem caráter social e individual.

É preciso salientar que o estudo, como qualquer outro, possui limites, no caso determinados principalmente pela forma como se deu a entrada no cenário de pesquisa e pela inviabilidade de um debate coletivo com os participantes a respeito de suas produçóes, o que contrariou as expectativas iniciais das pesquisadoras. Em contrapartida, o fato de a coleta de dados ter se dado de modo um tanto conturbado reflete, em certo aspecto, como as demandas de saúde mental costumam chegar aos serviços públicos de saúde no âmbito da APS, especialmente aquelas apresentadas por usuários com diagnóstico de esquizofrenia. Isso, em última instância, involuntariamente criou um contexto interessante para o presente estudo. E cabe lembrar que as pesquisas qualitativas, via de regra, dizem respeito a uma realidade 
que se constrói mediante a relação estabelecida entre o pesquisador e os participantes, razão pela qual os achados de pesquisas futuras poderão se revelar compatíveis ou não com os resultados aqui reportados. ${ }^{1}$

\section{Agradecimentos}

Ao Conselho Nacional de Desenvolvimento Científico e Tecnológico (CNPq), pela bolsa de produtividade em pesquisa concedida ao quarto autor, cujos recursos apoiaram a realização do estudo.

\section{Referências}

AIELLO-VAISBERG, T. M. J. Encontro com a loucura: transicionalidade e ensino de Psicopatologia. 1999. Tese (Livre-docência em Psicopatologia) - Instituto de Psicologia, Universidade de São Paulo, São Paulo, 1999.

AIELlO-VAISBERG, T. M. J.; AMBROSIO, F. F. Imaginários coletivos como mundos transicionais. In: AIELLO-VAISBERG, T. M. J.; AMBROSIO, F. F. (Orgs.). Cadernos Ser e Fazer: imaginários coletivos como mundos transicionais. São Paulo: IPUSP, 2006. p. 5-8.

- Rabiscando Desenhos-Estórias com Tema: pesquisa psicanalítica de imaginários coletivos. In: TRINCA, W. (Org.). Procedimento de Desenhos-Estórias: formas derivadas, desenvolvimentos e expansões. São Paulo: Vetor, 2013. p. 277-302.

AMARANTE, A. L. et al. As estratégias dos enfermeiros para o cuidado em saúde mental no Programa Saúde da Família. Texto \& Contexto Enfermagem, Florianópolis, v. 20, n. 1, p. 85-93, 2011.

AMARANTE, P.; NUNES, M. O. A reforma psiquiátrica no SUS e a luta por uma sociedade sem manicômios. Ciência \& Saúde Coletiva, Rio de Janeiro, v. 23, n. 6, p. 2067-2074, 2018.

ALMEIDA, G. H. Acolhimento e tratamento de portadores de esquizofrenia na Atenção Básica: a visão dos gestores, terapeutas, familiares e pacientes. 2010. Tese (Doutorado em Saúde Pública) - Faculdade de Saúde Pública, Universidade de São Paulo, São Paulo, 2010.

ARAÚJO, M. F.; LEMOS, A. C. S.; CARVALHO, C. M. L. O relacionamento terapêutico no cuidado dispensado a um esquizofrênico: narrativas de um diário de campo. Revista Brasileira em Promoção da Saúde, Fortaleza, v. 20, n. 2, p. 116-123, 2007.

BRASIL. Portaria n. 3.088/2011, de 23 de dezembro de 2011. Diário Oficial da União. Brasília, 2011.

CAMPOS, D. B.; BEZERRA, I. C.; JORGE, M. S. B. Produção do cuidado em saúde mental: práticas territoriais na Rede Psicossocial. Trabalho, Educação e Saúde, Rio de Janeiro, v. 18, n. 1, e0023167, 2020. 
CASTRO, S. A.; FUREGATO, A. R. F. Conhecimento e atividades da enfermagem no cuidado do esquizofrênico. Revista Eletrônica de Enfermagem, Goiânia, v. 19, n. 4, p. 957-965, 2008.

CLARK, J. P. How to peer review a qualitative manuscript. In: GODLEE, F.; JEFFERSON, T. (Orgs.). Peer review in Health Sciences. London: BMJ Books, 2003. p. 219-235.

ENRIQUEZ, E. Psicanálise e ciências sociais. Ágora: Estudos em Teoria Psicanalitica, Rio de Janeiro, v. 8, n. 2, p. 153-174, 2005.

FERNANDES, A. D. S. A.; MATSUKURA, T. S.; LOURENÇO, M. S. G. Práticas de cuidado em saúde mental na Atenção Básica: identificando pesquisas no contexto brasileiro. Cadernos Brasileiros de Terapia Ocupacional, São Carlos, v. 26, n. 4, p. 904-914, 2018.

GAMA, C. A. P.; ONOCKO-CAMPOS, R. T.; FERRER, A. L. Saúde mental e vulnerabilidade social: a direção do tratamento. Revista Latinoamericana de Psicopatologia Fundamental, São Paulo, v. 17, n. 1, p. 69-84, 2014.

GIACON, B. C. C.; GALERA, S. A. F. Primeiro episódio da esquizofrenia e assistência de enfermagem. Revista da Escola de Enfermagem da USP, São Paulo, v. 2, n. 40, p. 286-291, 2006. GRANATO, T. M. M.; TACHIBANA, M.; AIELlO-VAISBERG, T. M. J. Narrativas interativas na investigação do imaginário coletivo de enfermeiras obstétricas sobre o cuidado materno. Psicologia \& Sociedade, Florianópolis, v. 23, n. spe., p. 81-89, 2011.

HERRMANN, F. Andaimes do real: o método psicanalítico. $3^{a}$ ed. São Paulo: Casa do Psicólogo, 2001.

. Sobre os fundamentos da Psicanálise: quatro cursos e um preâmbulo. São Paulo: Blucher, 2017.

JUCÁ, V. J. S.; NUNES, M. O.; BARRETO, S. G. Programa de Saúde da Família e Saúde Mental: impasses e desafios na construção da rede. Ciência \& Saúde Coletiva, Rio de Janeiro, v. 14, n. 1, p. 173-182, 2009.

LAPLANCHE, J.; PONTALIS, J. B. Vocabulário da psicanálise. Tradução de Pedro Tamen. $3^{a}$ ed. São Paulo: Martins Fontes, 2000.

LEAL, E. M.; SERPA Jr, O. D. Psicopatologia e Reforma Psiquiátrica: uma experiência de ensino protagonizada por quem vivencia o sofrimento psíquico. Cadernos Brasileiros de Saúde Mental, Florianópolis, v. 2, p. 57-65, 2009.

LIMA, D. U.; GARCIA, A. P. R. F.; TOLEDO, V. P. Olhares da enfermagem para o paciente esquizofrênico: implicaçóes do processo saúde doença para o cuidado. Revista de Enfermagem UFPE, Recife, v. 7, n. 55, p. 4325-4331, 2013.

MANNA, R. E.; LEITE, J. C. A.; AIELLO-VAISBERG, T. M. J. Imaginário coletivo de idosos participantes da Rede de Proteção e Defesa da Pessoa Idosa. Saúde e Sociedade, São Paulo, v. 27, n. 4, p. 987-996, 2018. 
MARTINS, A. C. R. et al. Percepção do enfermeiro na Atenção Primária sobre as pessoas com esquizofrenia. Revista de Iniciação Científica da Libertas, São Sebastião do Paraíso, v. 8, n. 1, p. 87-107, 2018.

MATUMOTO, S. et al. A prática clínica do enfermeiro na atenção básica: um processo em construção. Revista Latino-Americana de Enfermagem, Ribeirão Preto, v. 19, n. 1, p. 1-8, 2011.

OLIVEIRA, A. G. B.; ALESSI, N. P. O trabalho de enfermagem em saúde mental: contradiçóes e potencialidades atuais. Revista Latino-Americana de Enfermagem, Ribeirão Preto, v. 11, n. 3, p. 333-340, 2003.

OLIVEIRA, A. G. B.; ATAÍDE, I. C.; SILVA, M. A. A invisibilidade dos problemas de saúde mental na Atenção Primária: o trabalho da enfermeira construindo caminhos junto às equipes de Saúde da Família. Texto \& Contexto Enfermagem, Florianópolis, v. 13, n. 4, p. 618-624, 2004.

ONOCKO-CAMPOS, R. T. Saúde mental no Brasil: avanços, retrocessos e desafios. Cadernos de Saúde Pública, Rio de Janeiro, v. 35, n. 11, e00156119, 2019.

ORGANIZAÇÃO MUNDIAL DA SAÚDE. Classificação de transtornos mentais $e$ de comportamento da Classificação Internacional de Doenças (CID-10): descriçóes clínicas e diretrizes diagnósticas. Porto Alegre: Artes Médicas, 1993.

PONTES, M. L. S. et al. A gravidez precoce no imaginário coletivo de adolescentes. Psicologia: Teoria e Prática, São Paulo, v. 12, n. 1, p. 85-96, 2010.

RIBEIRO, D. P. S. A.; TACHIBANA, M.; AIELLO-VAISBERG, T. M. J. A experiência emocional do estudante de psicologia frente à primeira entrevista clínica. Aletheia, São Leopoldo, v. 28, p. 135-145, 2008.

ROSA, D. C. J. et al. O conceito de imaginário coletivo em sua acepção psicanalítica: uma revisão integrativa. Psicologia Clínica, Rio de Janeiro, v. 31, n. 3, p. 577-595, 2019.

RUSSO, R. C. T.; COUTO, T. H. A. M.; AIELlO-VAISBERG, T. M. J. O imaginário coletivo de estudantes de educação física sobre pessoas com deficiência. Psicologia \& Sociedade, Florianópolis, v. 21, n. 2, p. 250-255, 2009.

SERPA JR, O. D. et al. Relatos de experiências em recovery: usuários como tutores, familiares como cuidadores/pesquisadores e efeitos destas práticas em docentes e pesquisadores em saúde mental. Cadernos Brasileiros de Saúde Mental, Florianópolis, v. 9, n. 21, p. 250-270, 2017.

SIMÓES, C. H. D. Sofredores, impostores e vitimas da sociedade: imaginário de uma equipe de saúde mental sobre o paciente psiquiátrico. 2012. Tese (Doutorado em Psicologia) - Centro de Ciências da Vida, Pontifícia Universidade Católica de Campinas, Campinas, 2012.

TACHIBANA, M. Fim do mundo: o imaginário coletivo da equipe de enfermagem sobre a gestação interrompida. 2011. Tese (Doutorado em Psicologia) - Centro de Ciências da Vida, Pontifícia Universidade Católica de Campinas, Campinas, 2011. 
TANAKA, O. Y.; RIBEIRO, E. L. Açôes de saúde mental na atenção básica: caminho para ampliação da integralidade da atenção. Ciência \& Saúde Coletiva, Rio de Janeiro, v. 2, n. 14, p. 477-486, 2009.

TESSER, C. D.; POLI NETO, P.; CAMPOS, G. W. S. Acolhimento e (des)medicalização social: um desafio para as equipes de saúde da família. Ciência \& Saúde Coletiva, Rio de Janeiro, v. 15, supl. 3, p. 3615-3624, 2010.

\section{Nota}

${ }^{1}$ D. C. J. Rosa: concepção e desenho da pesquisa, coleta, análise e interpretação de dados, redação e revisão do texto. D. M. Lima: coleta, análise e interpretação de dados e redação do texto. L. Miranda: análise e interpretação de dados e redação e revisão do texto. R. S. Peres: concepção e desenho da pesquisa, análise e interpretação dedados, redação e revisão do texto. 


\section{Abstract}

\section{"Problem-patient": collective imaginary of nurses about the user diagnosed with schizophrenia}

This study aimed to understand beliefs and emotions about the user diagnosed with schizophrenia current in the collective imaginary of nurses working in Primary Health Care. It is a qualitative study based on the psychoanalytic investigative method. The participants were 15 nurses who worked at the referred level of health care in a medium-sized city. Data collection was performed using the Drawing-Story with Theme Procedure (PDE-T) and data analysis sought to capture fields of meaning through the execution of the technical movements recommended for the operationalization of the psychoanalytic investigative method. It was found that, in a non-conscious way, the user diagnosed with schizophrenia is negatively represented in the collective imaginary of the participants, because he is seen as an inconvenient person, who creates uproar and arouses fear, mainly due to his supposedly typical "agitation". Thus, facing such a user means, for the participants, a situation to be quickly "solved". Therefore, this study highlights difficulties concerning mental health care offered to users diagnosed with schizophrenia, which are related to non-conscious elements of group subjectivity that, at the same time, have a social and individual character.

> Keywords: collective imaginary; nursing; mental health; primary health care; schizophrenia. 